\title{
El revival de la historia social en la primera década del siglo XXI: ¿̇etorno o reconfiguración?
}

\author{
The revival of Social History in the first decade of the $21^{\text {st }}$ century: return \\ or reconfiguration?
}

\author{
Beatriz I. Moreyra \\ beamoreyra@fibertel.com.ar \\ Investigador Principal \\ Centro de Estudios Históricos "Prof. Carlos S. A. Segreti" - Unidad Asociada al Consejo Nacional \\ de Investigaciones Científicas y Técnicas (CONICET) \\ Calle Miguel C. del Corro, 308 \\ 5000 - Córdoba \\ Argentina
}

\section{Resumen}

Esta contribución tiene como objetivo reflexionar sobre el status de la historia social en la primera década del siglo XXI, después del fuerte impacto de las corrientes revisionistas de las últimas décadas del siglo XX en la construcción del conocimiento histórico, que produjeron una devaluación de la importancia y alcance del adjetivo "social" desde el punto de vista teórico, empírico e inclusive político. Estas reflexiones se enmarcan en un contexto caracterizado por las profundas transformaciones que han experimentado las sociedades contemporáneas y a las que la disciplina histórica ha respondido con nuevos enfoques, renovados presupuestos metodológicos y dudas epistemológicas. Esta empresa implica una redefinición y revitalización del concepto de lo social, reconfiguración disciplinar que involucró, entre otros, los siguientes aspectos: un renovado deslizamiento hacia lo social como categoría analítica central, la tendencia hacia aproximaciones transnacionales y la politización de los procesos sociales.

\section{Palabras clave}

Historia social; Historiografía; Historia cultural.

\begin{abstract}
The purpose of this contribution is to reflect on the status of Social History in the first decade of the $21^{\text {st }}$ century. In the late $20^{\text {th }}$ century, revisionist theories had a strong influence on the construction of historical knowledge, resulting in a depreciation of the social factor in the theoretical, empirical and even political aspects of such construction. These reflections appear in a context marked by the profound changes experienced by the contemporary societies, and in that regard, the historical discipline provided new approaches, renewed methodological assumptions and epistemological questions to such changes. The social aspects of the discipline have been redefined and strengthened, and this reconfiguration places social factors as a key analytical category, while it tends to approach the social processes from a transnational perspective and to politicize them.
\end{abstract}

Keywords

Social history; Historiography; Cultural history.

Recibido el: 19/2/2014

Aprobado el: 31/3/2014 
Esta contribución tiene como objetivo reflexionar sobre el status de la historia social en la primera década del siglo XXI, después del fuerte impacto de las corrientes revisionistas de las últimas décadas del siglo $X X$ en la construcción del conocimiento histórico. Estas reflexiones se enmarcan en un contexto caracterizado por las profundas transformaciones que han experimentado las sociedades contemporáneas y a las que la disciplina histórica ha respondido con nuevos enfoques, renovados presupuestos metodológicos y dudas epistemológicas. La revolución cultural de 1968 y, posteriormente, la caída del muro de Berlín y el desmantelamiento del imperio soviético causaron grandes impactos sobre los órdenes políticos, económicos, sociales y culturales y la historiografía de la última década del siglo XX y la primera del XXI no fueron inmunes a esos reordenamientos (IGGERS 2010, p. 112). En efecto, la historiografía social ha vivido una profunda conmoción como consecuencia del agotamiento de las formas de historiar dominantes y la eclosión de diferentes candidatos a ocupar dicha hegemonía. A pesar de ello, en la primera década del presente siglo, la disciplina ha encarado por fin una deriva de recomposición tras más de una larga década de crisis, si bien no ha surgido en el horizonte una alternativa suficientemente compartida como para convertirse en un nuevo programa hegemónico de alcance global.

En ese sentido, quisiera hacer unas precisiones sobre el alcance de estas reflexiones. En un clima permeado por un policentrismo temático y metodológico, lo que se ofrece es una mirada y no la mirada sobre los problemas inherentes a la construcción del conocimiento sociohistórico, abordaje que, como lo expresa Michel de Certeau, se refiere siempre a la combinación de un lugar social, prácticas científicas y una escritura. Por lo tanto, en este recorrido historiográfico, he optado por visitar algunos lugares sacrificando otros, de modo que habrá ausencias dentro y fuera del recorte seleccionado.

\section{El eclipse de la historia sociocientífica y el impacto del giro cultural en la historiografía social}

En la segunda mitad del siglo $X X$, es dable distinguir dos etapas en los debates teórico-metodológicos más contemporáneos en el campo de la historia social. Los años 60 y 70 del siglo pasado significaron para los estudios sociohistóricos el predominio de las concepciones fuertes de la causalidad, la determinación y de la totalidad social y la prioridad analítica del contexto social. En esa perspectiva, la denominada historia sociocientífica se propuso aplicar el paradigma estructuralista, abiertamente reconocido o implícito en la práctica, al estudio de las sociedades antiguas o contemporáneas; la tarea del historiador era identificar las estructuras y las relaciones que operaban, independientemente de las percepciones e intenciones de los individuos, para gobernar los mecanismos económicos, organizar relaciones sociales y engendrar formas de discurso. Esas arquitecturas integradoras garantizaban la posibilidad de una inteligibilidad global de lo social porque el contexto social operaba como fundamento causal de lo subjetivo y, por lo tanto, las acciones humanas no eran meros actos de voluntad, sino efectos de las condiciones sociales de existencia. Desde ese 
punto de vista, los sujetos eran siempre sujetos sociales y era en sus atributos y posiciones sociales que debía buscarse la explicación de su conciencia, de su identidad y de sus prácticas.

Ejemplos claros de esa historia estructural fueron los trabajos de William Sewell y de Joan Scott, autores que paradójicamente se convirtieron en los años 80 y 90 en la punta de lanza de los revisionismos. Sewell, en su obra Marsella, estructura y movilidad, ofrecía una versión socioestructural de la industrialización urbana entre los años 20 y 70 del siglo XIX en la que el autor utilizaba sofisticados métodos cuantitativos para resaltar las cambiantes jerarquías ocupacionales, modelos de inmigración y perspectivas de movilidad social. Esa investigación buscaba situar la emergencia y desarrollo de la conciencia obrera dentro de una explicación estructural de todos los procesos subyacentes, cuyas consecuencias se consideran determinantes.

Pero, a partir de los años 70, los historiadores ya no procedían del mismo modo; su dependencia de las estructuras preexistentes para explicar la historia fue deslegitimada. Es decir, la antigua creencia de que las acciones de la gente se explicaban mejor por su situación social, por sus identidades sociológicas, por su pertenencia a categorías sociales objetivas, en términos socioestructurales o simplemente materialistas, pasó a ser muy cuestionada. El recurso cada vez menor al viejo materialismo explicativo abrió un espacio de fructífera indeterminación, en la que otros tipos de pensamiento podían crecer (ELEY 2010, p. 159).

En ese clima intelectual, una perspectiva antiestructural con fuerte impacto cultural e implicancias culturalistas se hizo sentir en muchas esferas de la vida y condujo a un deslizamiento generacional y paradigmático. En efecto, la historia social posbraudeliana experimentó el impacto del giro cultural que produjo una reorientación de la investigación sociohistórica hacia el estudio de los dispositivos culturales, simbólicos y mentales y cuya perspectiva analítica se centraba en la interpretación de las significaciones históricas. Así cobró auge en esas décadas un movimiento de recuperación del análisis cultural como perspectiva de estudio capaz de intervenir de un modo significativo en algunos de los campos de discusión centrales dentro de las ciencias sociales. El resquebrajamiento del amplio proyecto consensual de la historia social y de la causalidad social se hizo sentir en historiadores que, formados en la perspectiva estructural, como Scott, Sewell y Stedman Jones, entre otros, evidenciaron lo problemática que resultaba la soberanía de lo social. Para los años 80 , Stedman Jones se había apartado claramente de su compromiso con el análisis de la historia social de lo político y había demostrado la imposibilidad de explicar la política tal como lo hacían los sociólogos, que interpretaban que el cartismo derivaba de las relaciones de clase y de los cambios sociales de la economía. Otro caso paradigmático fue el den las reflexiones de Joan Scott y su compromiso con la primacía analítica del lenguaje, que lo llevó a privilegiar de manera estrecha el texto concreto y las formas de subjetividad que ese mismo texto se suponía que contenía. En esa línea argumental, ella centró su interés decidida y persistentemente en el proceso de construcción de las subjetividades propiamente dichas. Además, 
afirmaba que lo más importante era cómo las subjetividades de la posición de clase llegaban a construirse lingüística y culturalmente. También ese viraje se percibió en Alemania, donde emergieron, como un reto a la historia social de la Escuela de Bielefeld, de enfoque macro y estructural, los trabajos de Hans Medick y Alf Lüdtke, entre otros. Así, en 1976, Lutz Niethammer junto a Brüggemeir realizaron un extraordinario estudio sobre la vivienda de la clase obrera, que traspasaba la vida social del partido y el sindicato, normalmente asociados a la formación de la conciencia obrera, y en el que sostuvieron que, para entender las formas características de esa conciencia, era necesario explorar los escenarios informales de la cotidianeidad de los trabajadores (LÜDTKE 1995).

Así, la historia devino más importante como una fuente de identidad colectiva que como un medio para dar cuenta de la variabilidad de la experiencia histórica.

\section{Límites y costos explicativos del giro cultural}

Esa revalorización del papel de la cultura y del lenguaje fue tan útil como engañosa.

La incorporación de esos virajes en la práctica historiográfica ha sido, sin dudas, decisiva. Además, el peligro subyacente a todo revisionismo es el de convertirse en una nueva ortodoxia. A la historiografía emergente de dichos cambios se le cuestiona la fragmentación del objeto de conocimiento en una amalgama de novedades de moda, el desarme teórico y político y la práctica de sobreargumentar la historia de la gente común con el consiguiente riesgo de opacar la consideración más amplia de la estructura y el poder social, relegando la síntesis interpretativa.

En el caso concreto de Scott, su libro sobre las feministas francesas, Solo paradojas para ofrecer, no es representativo de la versión más ambiciosa del programa que parecían sugerir sus críticas epistemológicas, porque en esa obra solo se evidencia cómo los sujetos políticos se producen en el plano discursivo más familiar y no se explican, en su evaluación crítica del pensamiento y las carreras de varias feministas francesas, los importantes contextos sociales más amplios en los que se dio la producción de esos sujetos políticos. Es decir, Scott dejaba de lado las cuestiones relacionadas con el capitalismo, el Estado, el lugar de la coerción en la vida política, la reproducción estructurada de mayor desigualdad social y económica y la capacidad que tienen las poblaciones concretas para la acción colectiva.

Críticas semejantes podemos encontrar en Stedman Jones. Su argumento con respecto a que es necesario prestar atención a los lenguajes de los actores políticos reales es convincente porque devuelve la voz y la acción a los movimientos políticos en términos de su propia formación discursiva y de sus prácticas lingüísticas, pero le falta conectar la clase entendida discursivamente con la clase como componente de las relaciones estructurales de Inglaterra en los años cuarenta del siglo XIX.

Para Núñez-Seixas, en su balance sobre la historia social, las dos décadas de predominio del enfoque cultural de los fenómenos sociales han brindado como aporte el análisis de los imaginarios y las mentalidades y la aprehensión 
de las identidades colectivas y su evolución, pero también han creado nuevos problemas, como el de la sustitución de la explicación estructural por "un relativismo poco explicativo" que conlleva el olvido de las estructuras y el predominio de las percepciones; la atribución de un papel autónomo a la cultura y a los imaginarios; el desconocimiento de los factores independientes de la voluntad de los individuos que limitan e incluso "determinan" su acción; la pérdida de protagonismo de los sujetos colectivos; y el regreso al "individualismo metodológico más esquemático" (NúÑEZ-SEIXAS 2008, p. 180-181).

Pero es interesante mencionar que hubo dos actitudes diferenciadas por parte de los historiadores sociales frente al giro culturalista. Por un lado, la de aquellos que, si bien insisten en la necesidad de pensar la esfera de la subjetividad desde nuevos parámetros e introducen importantes matices respecto a la teoría de la sociedad con la que trabajaban, no anidan una vocación rupturista con relación a las prácticas precedentes; más bien adoptan una prolongación crítica que hace bascular el modelo de conocimiento hacia la esfera del sujeto con el fin de establecer un equilibrio o mediación entre ambas instancias ignorado por el "imperio del objeto" (ESTRELLA GONZÁLEZ 2005, p. 147-179), prevaleciente en la historia sociocientífica. Es decir, la mayoría de los historiadores socioculturales nunca abandonó la creencia en la realidad objetiva del mundo social. Por el contrario, una segunda actitud fue abiertamente rupturista. En esa perspectiva, el entusiasmo por los enfoques interpretativos y, sobretodo, el desplazamiento del foco de la investigación desde el fenómeno social al discurso llevaron a borrar las diferencias entre el giro cultural y el giro lingüístico. En efecto, desde la década de los 90 del siglo XX somos testigos de cómo en diferentes ámbitos intelectuales y científicos eclosionan propuestas que comienzan a cuestionar los principios de la epistemología representacionista. Su irrupción en el campo historiográfico contribuiría decisivamente al agotamiento de los paradigmas de la historia social y sociocultural.

En efecto, la creciente atención al lenguaje y a las estructuras discursivas cuestionó el modelo causal de la vieja historia social y buscó sustituirlo por modelos discursivos de cultura que proclamaban, con la ayuda de la lingüística saussuriana, la naturaleza culturalmente construida de la sociedad y de la experiencia individual. Ese reduccionismo culturalista, por la vía de la ortodoxia textual, sostenía que el discurso "producía" al sujeto, que éste no constituía un agente dotado de libertad y conciencia, sino que era más bien una posición creada por el discurso, perspectiva que se exterioriza en la idea de muerte o desaparición del sujeto de Foucault. En otras palabras, ontologizaba lo cultural (MOREYRA 2011).

En síntesis, las propuestas de los pensadores de la posmodernidad constituyeron una respuesta radical a las debilidades de la ciencia social clásica con su mirada exclusivamente estructural de las realidades sociales y sostenían que estas deberían ser sustituidas por constructos retóricos que narrasen la vida y la significasen sin que fuera necesario ir más allá. 


\section{Más allá del culturalismo: la reconfiguración de la historia social en la primera década del siglo XXI}

A partir de 1990, hubo un claro distanciamiento de las formas extremas de culturalismo, del primado del lenguaje imperante en las décadas de los años 70 y 80 y del subsecuente radicalismo del relativismo epistemológico. Es decir, la influencia del culturalismo extremo, en el contexto de un mundo modificado por la caída del muro de Berlín y los reordenamientos del mundo soviético, comenzó a batirse en retirada en la teoría de las ciencias sociales y en la de la historiografía (BONNELL; HUNT 1999; SPIEGEL 2005).

El cuestionamiento al relativismo radical emerge aun en la producción historiográfica de los mismos simpatizantes del giro cultural. En el caso de la historiadora feminista Joan Scott, si bien ella defendía la relativización de todo saber, es autora de algunas investigaciones sobre la historia social de la mujer en Francia en la primera mitad del siglo XIX y sobre su papel en la política que contradicen el relativismo epistemológico (IGGERS 2010, p. 112). Es decir, aunque la influencia del giro cultural haya sido profunda entre los historiadores sociales, ellos han rechazado la eliminación de lo social que las formas más radicales de culturalismo o posestructuralismo llevaron a cabo (BONNELL; HUNT 1999, p. 12). Lo cierto es que veinticinco años después de la adopción del giro lingüístico, hay una creciente insatisfacción con respecto a esa aproximación sistemática de la operación lingüística en el dominio de los emprendimientos humanos de cualquier tipo; es decir, pocos están dispuestos a adherir ortodoxamente al supuesto epistemológico de que el lenguaje no sólo modela la realidad histórica, sino que la constituye, o de que la creación de significados es impersonal y opera a espaldas de los usuarios del lenguaje. Además, no obstante la importancia reservada a lo cultural, asistimos hoy a una revitalización de lo social que es también una redefinición ontológica y metodológica. Cobra fuerza el supuesto de que la reconstrucción de las acciones y percepciones es indispensable en la construcción del conocimiento histórico pero que dicha reconstrucción no suprime el análisis de las estructuras y procesos que condicionan esas acciones y percepciones.

Por otra parte, los historiadores sociales advierten que la perspectiva sociocultural, en su esfuerzo por concentrarse en los márgenes de la sociedad como una manera para deconstruir el centro, ha reducido la importancia de éste. Es decir, las conexiones se han vuelto poco claras en vez de volverse decisivas por medio del detalle histórico eficaz. Por otra parte, el giro culturalista en algunas producciones de historia social lleva con frecuencia a privilegiar partes excéntricas de las evidencias, examinadas cuidadosa e intensivamente, pero no se advierte el mismo énfasis en mostrar cómo el desempeño cultural está conectado a la sociedad (FASS 2003, p. 43). La decepción con respecto a algunos aspectos del giro cultural ha producido un nuevo viraje, no en dirección hacia prácticas precedentes, sino hacia una reconfiguración de la categoría de lo social que, como lo expresan Bonnell y Hunt, requiere ser investigada en el sentido de cómo es vivida y reconstruida por medio de las prácticas concretas (FASS 2003, p. 14). 
Esta empresa implicó una redefinición y revitalización del concepto de lo social, reconfiguración disciplinar que involucró, entre otros, los siguientes aspectos: un renovado deslizamiento hacia lo social como categoría analítica central, la tendencia hacia aproximaciones transnacionales y la politización de los procesos sociales.

\section{La recuperación de lo social}

En el primer aspecto mencionado, la revalorización de la capacidad explicativa del contexto cobra vigencia porque, sin la apelación a las reconstrucciones de los contextos históricos, el caso individual culturalmente resonante no puede hacerse históricamente significativo. Toda percepción, toda construcción de significado, ocurre dentro de contextos históricamente contingentes y sociológicamente situados, producidos por agentes que actúan como actores intencionales y resignificantes semánticos de los sistemas de signos y discursos históricamente construidos. Es decir, si bien la crítica posmoderna contra las pretensiones universalizadoras y totalizadoras del racionalismo, contra la pasión globalizante de la ciencia moderna, es ciertamente válida, también es igualmente cierto que se ha comenzado a poner distancia crítica con respecto a la diferenciación extrema que postulan algunos pensadores posmodernistas y que impide percibir el mundo por encima de los límites de sus fenómenos recurrentes y poner éstos en relación unos con otros. Los cambios metodológicos delineados representaron avances considerables en una visión más abarcadora y compleja de lo social y en el debilitamiento del enfoque simplificador, pero no produjeron una salida integradora, sino que, presentándose como alternativas opuestas a las perspectivas precedentes, significaron un desplazamiento progresivo hacia estudios micro y locales, el énfasis en los particularismos, la acentuación de la fragmentación, la atomización del conocimiento, la deslegitimación de universales y la entronización de un relativismo cultural, localista y de actores focales que deja afuera la preocupación por la noción de totalidad y los fines más globales del conocimiento social (ESPINA PRIETO 2005, p. 91-92).

Contemporáneamente, existe un posicionamiento más alentador que considera que lo que está en crisis no es la posibilidad de construir un conocimiento sobre lo social, sino una forma específica de construir ese conocimiento cuando se toma conciencia de que lo cultural deja de ser incluyente para volverse excluyente de lo social; de allí la apelación a integrar esa dimensión en la totalidad social, volviendo a prestar más atención a los métodos de las ciencias sociales que constituyen herramientas insustituibles para un análisis realista de los aspectos globales y de las especificidades locales.

Enfrentados a la creciente "balcanización de la disciplina y de las reconstrucciones históricas, se rescata la importancia de la capacidad explicativa del contexto. En otras palabras, la reformulación de lo social en cuestión implica la necesidad de ponderar el poder condicionante y explicativo de las realidades sociales no discursivas que imponen límites. En términos teórico-metodológicos, ello implica la necesidad de no excluir la causación social en la explicación de las realidades sociales. En esta línea argumental, Sewell expresa que: 
[...] el método fundamental para comprender lo social es interpretativo. Es decir, debe explicar las realizaciones humanas mediante la reconstrucción de los códigos semióticos que las hicieron posibles. Pero este enfoque interpretativo debe ser ampliado para abarcar a los "entornos construidos" que son el efecto de esas realizaciones, es decir, a la construcción social y a la historia de las matrices materiales de la interacción humana. Redefinido de este modo, lo social continuaría dentro del amplio marco epistemológico establecido por el giro lingüístico, pero permitiría a los historiadores abordar, de una manera novedosa, una serie de problemas relevantes que preocupan a la vieja historia social, pero que han sido dejados de lado por los autores adheridos al giro lingüístico (SEWELL 2006, p. 71-72).

Esta apelación a los entornos construidos de Sewell aúna una explicación de cómo el mundo social es construido en el curso de la acción humana significativa y una explicación de la forma en que esa construcción cristaliza en instituciones $y$ en formas materiales de existencia humana. En ese sentido, Keith Michael Baker señala que la defensa que Sewell hace de esa perspectiva en su libro Logics of History. Social Theory and Social Transformation (SEWELL 2005) ha tenido "la virtud de redefinir los términos de un debate, cuyos rendimientos venían siendo decrecientes, al mismo tiempo que ha construido un amplio marco teórico que ofrece para el futuro un espacio fructífero de cohabitación y de fecunda discusión" (BAKER 2006, p. 110).

Ese giro social que revaloriza el contexto, involucra también un giro hacia la revalorización de lo material, después de la fuerte desmaterialización de la realidad que produjo la aproximación exclusivamente textualista de los estudios culturales. En efecto, el énfasis creciente sobre el papel del lenguaje ha provocado un excesivo debilitamiento del contenido social de la historia y un olvido de las transformaciones en la estructura material de la vida social. De allí que actualmente se plantee recuperar algunas de las virtudes de la historia social (SEWELL 2006, p. 52).

En ese sentido, para Biernacki, la producción de significado se localiza en la intersección del lenguaje y la práctica material, tendencia, por otra parte, dominante en la historiografía social de la última década. Los recientes trabajos dedicados a la cultura material y sobre las prácticas culturales representan importantes esfuerzos destinados a repensar los constituyentes de la cultura y cómo la cultura se articula con el contexto social sin que ello signifique un retorno a la concepción de que la lógica económica o política determina la organización cultural. En ese sentido, los objetos y procesos materiales son portadores tanto de conocimiento como de relaciones sociales $y$, por consiguiente, de cultura (JOYCE 2006, p. 83).

El regreso hacia lo material y lo social es evidente en los recientes trabajos de Sewell, notablemente en un ensayo acerca de Geertz donde él recupera la materialidad de la ubicación de la simbolización por parte del antropólogo en la evolución de la mente humana:

Si Geertz tiene razón como yo realmente creo, los sistemas semióticos no son espirituales ni fantasmales ni imaginarios; ellos son también 
parte de la vida de nuestras especies como la respiración, la digestión o la reproducción. Esto sugiere que los materialistas deberían dejar de preocuparse y amar la simbolización (SUNY 2002 p. 31).

La rematerialización de la cultura implica indagar cómo la cultura adopta formas concretas y cómo ellas poseen códigos culturales más explícitos. De allí que la principal empresa intelectual y cognitiva involucrada en los primeros años del siglo XXI sea precisamente volver a reconstruir lo social, que implica la no aceptación de que el pasado pueda entenderse solamente como un contexto de percepciones, experiencias, discursos, acciones y significados, sin que se tenga en cuenta el contexto social en el cual se conforman.

Esos cambios en los aspectos ontológicos y epistemológicos implican desde el punto de vista teórico-metodológico la resignificación de las categorías de causalidad, cambio, agencia humana, subjetividad y experiencia, así como una interpretación revisada de la categoría central de discurso que enfatice menos los aspectos estructurales de las explicaciones lingüísticas y más sus usos pragmáticos (SPIEGEL 2005). El nuevo giro social adopta un concepto más amplio y matizado de la categoría discurso: tomando en consideración fenómenos complejos como las instituciones, los sucesos políticos y las actividades económicas, conciben el discurso como un campo de prácticas que exceden lo lingüístico. Las prácticas discursivas también implican patrones físicos, actividades mentales rutinarias, formas de comprensión, motivaciones y, por encima de todo, objetos que están conectados unos con otros. Ese nuevo giro hacia lo social, si bien rechaza la ortodoxia culturalista en su versión textualista, incorpora la causalidad cultural en la explicación de los fenómenos y procesos sociales, aunque modifica su alcance. En otras palabras, se rechaza la autonomía de los factores culturales.

En ese sentido, una expresión clara del nuevo viraje hacia lo social ha sido la reacción en la pasada década contra el concepto de cultura como un sistema de símbolos y significados y el consiguiente deslizamiento hacia una concepción de la cultura como una esfera de actividad práctica integrada por acciones intencionales, relaciones de poder, conflictos, contradicción y cambios.

Desde esa perspectiva, la cultura emerge menos como una estructura sistemática y más como un repertorio de competencias, una caja de herramientas, un régimen de racionalidad práctica o una serie de estrategias que guían la acción. En ese régimen, los símbolos y los signos son utilizados para identificar aquellos aspectos de la experiencia de los actores que son significativos, esto es, experiencialmente reales. También desde esta óptica, la investigación sociohistórica toma la práctica como el punto de partida del análisis social, dado que la práctica aparece como el espacio en el que se produce la intersección significativa entre la construcción discursiva y la iniciativa individual. Así, la pregunta teórica central no es si la cultura debe ser conceptualizada como práctica o como sistema de símbolos y significados, sino cómo conceptualizar la articulación entre el sistema y la práctica. Se trata de una nueva concepción de los procesos sociales y cognitivos, que conceptualiza que éstos no son proyecciones de las esferas subjetivas u objetivas ni el resultado de la actualización de códigos semióticos, sino efectos de situaciones de orden práctico. 
La naturaleza de dichos procesos responde a situaciones activas en las que se dan una serie de interacciones entre los individuos y entre éstos y su medio; interacciones en las que los individuos - dotados de unos determinados recursos económicos, sociales y cognitivos- eligen entre diferentes cursos de acción a partir de los cuales construyen espacios de objetividad y subjetividad. El conocimiento deja de entenderse como una representación de lo real y deviene una construcción cuyas reglas se definen en el curso de prácticas intersubjetivas.

De acuerdo a esa perspectiva —que algunos autores denominan giro práctico-, el mundo social está primero y sobre todas las cosas poblado de diversas prácticas sociales llevadas a cabo por los agentes. De esa manera, la teoría de las prácticas evita que la teoría cultural se deslice por el sendero del culturalismo o el idealismo (SPIEGEL 2005, p. 258). Además, se insiste en que la normatividad que regula la producción de conocimientos no es, exclusivamente, efecto retórico de las formas y contenidos de la matriz discursiva, sino el resultado de situaciones prácticas de orden discursivo y no discursivo. En síntesis, la teoría de las prácticas, al poner el acento en la naturaleza históricamente constituida y siempre contingente de las estructuras, retrotrae a la clásica preocupación de la historiografía por los procesos, los agentes, el cambio y la transformación y a la consiguiente demanda de una investigación empíricamente fundada acerca de las particularidades sociales y culturales.

Ese énfasis en las prácticas como concepto articulador de las diferentes expresiones revisionistas está dando lugar, a su vez, a deslizamientos en la configuración interdisciplinaria, con un viraje desde una influencia decisiva de la antropología simbólica al influjo de una sociología y una teoría social que concibe a las sociedades como formaciones flexibles de prácticas que conectan a los humanos y a los no humanos en formas particulares de relación con el mundo; una sociología que está más atenta al carácter mutable, provisional y práctico de lo que acontece en el mundo social y a las explicaciones postuladas; una sociología que comprende la agencia como una relación históricamente cambiante entre un juego de recursos y otro de coerciones.

Si bien la teoría de las prácticas no ha logrado elaborar sistemáticamente el núcleo duro de esa aproximación a lo social, al menos ha generado un espacio de encuentro que permite aglutinar una serie de tendencias revisionistas no solo del campo de la historia, sino también de las ciencias sociales preocupadas por definir y resignificar el locus de lo social. Como ha sucedido a lo largo de los debates epistemológicos y metodológicos sobre la construcción del conocimiento social e histórico en particular, se ha avanzado por "senderos seguros" en la crítica a las insuficiencias explicativas de los modelos de comprensión histórica, pero más tímidamente en la configuración consistente de una nueva forma de abordaje. Jacques Revel comparte esa diagnosis y de alguna manera la considera como un antídoto contra una nueva ortodoxia:

El paisaje que ofrece hoy la historiografía francesa -y en este caso no es la única- es más bien el de una serie de obras a partir de las cuales pueden bosquejarse recomposiciones de amplitud variable. Hemos aprendido a vivir en esta contingencia y hasta encontrar en ella recursos heurísticos y críticos (REVEL 2005, p. 16). 


\section{Una historia social transnacional, una historia croisée}

A partir de 1990, y como consecuencia de la puesta en consideración de la capacidad explicativa de los contextos, la historia social retoma la perspectiva del horizonte de la totalidad como una forma de superar la extrema fragmentación disciplinar y el particularismo. Esta recuperada concepción de la totalidad no alude a la adopción de un a priori unificador y homogéneo, sino al resultado de las articulaciones del todo con las partes, que se construye históricamente. En ese contexto, se desarrolla una tendencia hacia aproximaciones transnacionales que abogan por un cambio desde lo microhistórico hacia lo comparativo, llamando inclusive a superar el marco nacional como unidad de análisis. En efecto, la característica central de esta práctica historiográfica es el deseo de trascender los marcos nacionales como categoría de análisis y evitar el etnocentrismo.

De allí deriva cierto interés por la denominada historia global que no es ajeno al impacto del proceso de globalización que promueve novedosas formas de interpenetración que trascienden las dimensiones estatales y nacionales, modifican las coordenadas espacio-temporales habituales por la multiplicación de ámbitos en los que se dan las relaciones sociales y por la pertenencia compartida de todos los colectivos a un mismo horizonte espacio-temporal. Pero más allá de la globalización, las ciencias sociales están volviendo a recuperar la importancia de las grandes historias, comprendiendo que la alternativa a la gran narración de la modernización no se encuentra en las migajas parceladas, como en su momento creyeron los posmodernistas, sino en el estudio de las interacciones

178 múltiples, más allá de las dimensiones estatales (VENGOA 2009, p. 302-304). Por otra parte, es importante destacar que lo global no se limita al objeto de estudio, sino a la intención de ir más allá de la fragmentación historiográfica y de los compartimentos disciplinarios. En ese sentido, la peculiaridad de la historia transnacional es que, en relación con la historia global y la historia mundial, el término "transnacional" alude a un sentido de movimiento e interpenetración. Esta forma de hacer historia permite posibilidades analíticas más amplias para comprender los complejos contactos, las redes y los actores (AHR 2006, p. 1444-1445). La idea central de esta perspectiva es su preocupación por los movimientos, flujos y circulaciones y no por un tema específico. Su unidad de análisis es el espacio de los flujos, perspectiva que implica no que los procesos históricos son construidos en diferentes espacios, sino que ellos son producto del movimiento entre lugares, sitios y regiones.

En ese sentido, el historiador alemán Jürgen Kocka afirma que las metáforas programáticas se expresan en "historias conectadas", "historias enredadas", "historia cruzada", "historia entrelazada", para designar enfoques que tratan de ser transnacionales (KOCKA 2003, p. 27). Hay una apelación creciente en la historia social contemporánea a reconstruir las interrelaciones, las circulaciones, las influencias mutuas, las interconexiones y los cruces de fronteras, preocupaciones exteriorizadas en las investigaciones sociales sobre los itinerarios, las migraciones, el crecimiento económico y las crisis de las ciudades, la cultura popular, los movimientos sociales, las redes y las dinámicas de recepción, apropiación y cambios resultantes de las interrelaciones. Hasta ahora 
parece más fácil aplicar ese enfoque al estudio histórico de las percepciones e influencias mutuas, las culturas y las ideas, que a las estructuras y los procesos sociales. Sin embargo, las recientes experiencias de internacionalización y la búsqueda creciente de enfoques transnacionales en el pensamiento, la investigación y la literatura histórica han hecho que los historiadores sociales comenzaran a enfrentarse a nuevos desafíos y oportunidades. Por una variedad de razones y en una variedad de maneras, los historiadores están reconsiderando sus marcos geográficos, obteniendo resultados que dan una nueva importancia a la comparación y a la habilidad para pensar en términos de conexiones globales o al menos interregionales. Es la llamada historia croisée, una historia relacional que se interroga sobre los vínculos entre diferentes formaciones constituidas históricamente. A partir de la idea de circulación, la historia transnacional ha provisto de una estrategia para superar el esquema binario de dominación y resistencia, ha multiplicado los focos de investigación desde el Estado a una variedad de actores transnacionales -individuos, comunidades, migrantes, organizaciones y grupos internos vinculados con homónimos externos- y no ha generado nuevas narraciones maestras ni interpretaciones teleológicas. En ese sentido, Sven Beckert afirma que la historia transnacional es "un modo de $v e r$ " que permite variadas preferencias, diferentes preguntas, tomando como punto de partida la interconexión y que, si bien no desconoce la importancia de los estados y otras formas estatales, pone el énfasis en las redes, procesos, creencias e instituciones que trascienden los espacios definidos políticamente. A partir de esta perspectiva, es posible dar nuevas interpretaciones a viejos y transitados temas. Además, ella ha adoptado diferentes aproximaciones y abraza una diversidad metodológica de acuerdo a la clase de interrogantes formulados. Sin embargo, todavía estamos lejos de que su práctica se convierta en un protocolo de experiencia generalizable.

\section{La politización de la historia social}

La historia social de los años 60 del siglo XX reificó la prioridad de lo social como la causa determinante de las identificaciones y subjetividades políticas. La práctica de la política, las instituciones y el lenguaje fueron reducidos al status de mera formalidad, a un reconocimiento o representación secundarios o a un reflejo de la identidad social que estaba dada. Las posiciones epistemológicas que tuvieron gran influencia en la formación académica profesional separaron lo social de lo político, minimizando el campo de lo político y generando toda una construcción de lo social, entendido como una esfera incontaminada donde los sujetos construían su propia historicidad (GIL PUJOL 1983, p. 65). Además, la escisión entre lo político y lo social diluyó lo político en lo estatal e hizo que la política se circunscribiera al estudio de los dominios exclusivos del funcionamiento del Estado y sus intermediarios o a los intercambios que el Estado mismo entablaba con aquello que era la "sociedad".

Pero, desde fines de la década de los años 70, los historiadores comenzaron a percibir las insuficiencias explicativas de aquellos trabajos que, deliberadamente o no, habían soslayado los factores políticos. Se impuso la 
necesidad de volver la atención a las dimensiones sociopolíticas del pasado, de reposicionar lo político que había sido excluido por el enfoque socioculturalista. Un sector cada vez más numeroso de la profesión postulaba la necesidad del retorno de lo político a la historia.

Entre los años 80 y los 90, la superación de la escisión entre lo social y lo político fue impulsada por el peso cada vez más grande adquirido por la dilatada esfera política en las sociedades contemporáneas, el acrecentamiento del campo de intervención de los Estados y, fundamentalmente, por la creciente politización de las situaciones en otros tiempos apolíticas. A ello se sumó la pérdida de influencia de los modelos marxistas y el hundimiento de todas las escatologías revolucionarias con fundamentos mecanicistas. Esa politización de los aspectos sociales se relacionó estrechamente con la renovación de la historia política, que buscaba ahora explorar la profundidad social de la política para encontrar manifestaciones de ella donde previamente se pensaba que no existían. En efecto, uno de los signos identitarios más importantes de esa nueva perspectiva fue la redefinición del concepto de hecho político, entendido ahora como un campo englobador y polimorfo abierto a todas las orillas de gestión de lo real y de las relaciones de poder. Se pondera que la política no se agota en el estudio de los aparatos del Estado. Por el contrario, estudiar históricamente la política implica preguntarse por sus bases sociales, por las luchas en torno a la definición del orden social y por el lugar que cada uno de los actores intenta darse en él. Lo político como fenómeno inseparable de lo social responde a aquello que justamente provocó las más severas críticas que recibiera la vieja historia: el pretender reducir el fenómeno político a individualidades descollantes, élites o pequeños grupos sin tener suficientemente en cuenta el entorno social en el cual se desarrolla y actúa el poder. Es decir, cobra fuerza la concepción de lo político como el lugar de gestión de la sociedad global al insistirse en el carácter creador de la decisión política en el seno de todas las demás actividades. Si no se reivindica la hegemonía de la política ni se pretende que todo sea político, sí se sostiene que lo político es el punto de encuentro de la mayor parte de las actividades sociales.

En ese sentido, Foucault, se interesó por la política no solo en términos de acumulación de poder económico o monopolización de la violencia estatal, sino también por las manifestaciones informales del ejercicio del poder detectadas en las diferentes relaciones sociales.

La recuperación de la política por los historiadores económicos y sociales tiene una identidad propia. El objeto ha sido replanteado y la política, redefinida, teniendo un significado mucho más amplio que el que se le adjudicaba tradicionalmente: es identificada directamente con el poder y con los hechos y circunstancias afines a él. Así, el objeto ha sido renovado, diversificado y relegitimado; más que hablar de la política corresponde aludir a lo político. De esa forma, se abre un amplio panorama para la investigación, porque los fenómenos políticos desbordan la estrechez de perspectivas de la historia convencional, en las cuales el problema político quedaba circunscrito prácticamente a las relaciones formales de poder. Por otra parte, lo político es visualizado como 
un proceso más que como una serie de eventos, prestándose atención a las permanencias y no solo a los cambios, en períodos de tiempo más bien largos. Ello condujo a un nuevo tipo de politización de los espacios antes considerados no políticos: el trabajo, el barrio, la subcultura, la familia, el hogar pasaron a verse como espacios donde el poder se organiza, se ejerce y se contesta. Eso significó también retomar la acepción de lo social desde abajo, como movimientos y actores sociales que construyen sus identidades desde lugares sociales que para nada son naturales. Esa repolitización de la historia social llevó a introducir nuevamente las categorías de hegemonía, resistencia, conflictos, negociación y acomodación de diversos poderes en disputa en las distintas localizaciones sociales (HERING TORRES; PÉREZ BENAVIDES 2012, p. 329).

Desde finales de los años 70 y principios de los 80 han existido dos caminos fundamentales para esa politización de la vida social. Uno era el abierto por la teoría del Estado, que supuso apreciar la implicación del Estado en la sociedad de forma ampliada, ensanchando los límites del gobierno para abarcar esferas de la administración social, de la salud pública, de la ley, de la escolarización, de la práctica religiosa, de la organización de la vida privada, de la sexualidad, de la diferencia entre lo público y lo privado. El segundo camino se ha recorrido a lo largo de varios tipos de culturalismo. Y es aquí donde la recepción de Foucault facilitó aún más la percepción de lugares más visibles del poder en un sentido más desmenuzado y cotidiano.

El poder y, por consiguiente, el significado político se organiza dentro y a través de todos los tipos de instituciones sociales y transacciones informales, así como a través de lugares más visibles y obvios de toma de decisiones. Por lo tanto, el poder ya no es propiedad del Estado, sino que puede encontrarse en la más pequeña e íntima de las relaciones humanas (ELEY; NIELD 2010, p. 172-175). Y, en este aspecto, es importante resaltar que la cultura no es apolítica. Las expresiones y prácticas culturales son también mecanismos de reproducción de las relaciones de poder imperante; es decir, la cultura es vista como una red de significaciones en las que se dirimen o refuerzan relaciones de poder. En ese sentido, las fiestas, los rituales, las conmemoraciones con sus productos y artefactos culturales - poesías, discursos, cánticos y otras formas literarias-, las actividades editoriales, los momentos de esparcimiento y los espacios de sociabilidad y de lectura constituyen herramientas culturales de profundas implicancias políticas e ideológicas.

Ese reconocimiento estimula el interés por la microhistoria, por las historias locales y cotidianas ocultas, porque es allí donde se puede acceder de forma realista y manejable a la dinámica de dichas relaciones y de su interconexión profana.

Por otra parte, la crítica feminista ha sido crucial a la hora de ampliar la categoría de lo político, al alejarse de la política en el anticuado sentido institucional y estatal y acercarse a otros lugares y situaciones en las que ocurre la contestación (la familia, la salud, la comida, la reproducción) y a otras temáticas de la historia social.

En síntesis, la historia social y la historia económica ya no son el estudio de una larga duración despolitizada, sino que, por el contrario, se reconoce 
la necesidad de analizar el rol del Estado, de las distintas instituciones y las relaciones de poder más informales y cotidianas en su calidad de actores cruciales en la conformación y evolución de las estructuras y coyunturas económicas y sociales, mediante sus políticas sectoriales y sus relaciones con los grupos sociales. Los historiadores sociales se acercaron a lo político con una nueva mirada, considerándolo no como un subcontinente desconectado de la historia social, sino como un lugar de gestión de la sociedad global. Sin reducir lo social o los movimientos sociales a sus manifestaciones y representaciones políticas, la política y lo político pueden ser el campo por excelencia en el que los sujetos colectivos, que solo han tenido existencia sociológica, devengan sujetos históricos en búsqueda de identidad y autonomía. Eso es posible porque la política no es solo ni principalmente el terreno contaminado por las influencias de la elite y del Estado; la política es por antonomasia un campo privilegiado de decantación y defensa de los intereses de las clases y grupos sociales. Desde esa perspectiva, sin constituirse en la columna vertebral de la historia, la política se transforma en un núcleo enriquecedor de la historia social.

\section{A modo de conclusión}

En la primera década del siglo XXI asistimos a una reconfiguración del locus de lo social que no implica desandar el recorrido del giro cultural en el estudio de los fenómenos sociales, sino, más fructíferamente, considerar la cultura como una categoría de la vida social distinta pero relacionada con la economía, la sociedad y la política. La cultura no es simplemente derivada de otras esferas, como lo podrían plantear los enfoques más objetivos, ni tampoco es reducible a causas materiales u otras no culturales, ni el problema de los significados se limita a los procesos estrictamente culturales o lingüísticos. Más fructíferamente, se puede considerar la cultura como un sistema de símbolos que poseen una coherencia real pero delgada que continuamente se pone en riesgo en la práctica y, por lo tanto, está sujeta a transformaciones (RECKWITZ 2002, p. 22). La cultura, como la sociedad, es un campo de juego con sus límites y sus armonías internas menos aparentes, en el cual actores y grupos compiten por posición y poder, concretamente, por el control de los significados. La cultura no es un objeto para ser descrito, ni es un cuerpo unificado de símbolos y significados homogéneo y atemporal. La cultura es, por el contrario, diversa, temporal y emergente.

Este nuevo giro social que busca la salvaguarda de la identidad de la historia social rechaza la autonomización de lo cultural y afirma que la cultura es profundamente comprometida con la historización. La comprensión viene con la contextualización cultural, espacial y temporal.

Los historiadores del siglo XXI se perfilan como receptivos al nuevo cambio cultural sin abrazar, sin embargo, los argumentos relativistas o antipositivistas más extremos de los antropólogos o críticos literarios (BRANTLINGER 2002, p. 15). Es decir, para evitar el peligro de la autonomización de la cultura y una falsa romantización del pasado, las interpretaciones culturales no deben ser divorciadas de lo que la gente realiza y de lo que le es impuesto por la 
fuerza. Los estudios históricos culturales deben siempre incluir un análisis de las circunstancias de vida, trabajo y autoridad bajo las cuales las personas actúan y elaboran sus interpretaciones.

Cuando se afirma que lo cultural es indisociable de lo social nos referimos a los intentos de eliminación de lo social que es insinuado por las formas más radicales de culturalismo y posestructuralismo, del mismo modo que cuando aludimos a un nuevo giro social no buscamos regresar a los paradigmas objetivos sino afirmar que todas las culturas poseen una dimensión material y que todo lo material realizado por los seres humanos tiene una dimensión cultural.

Lo que propicia esta reconfiguración de la historia social es la superación de los dualismos que predominaban en las ciencias sociales e históricas en particular; las dicotomías que han contrapuesto los factores objetivos, materiales, estructurales o institucionales a los subjetivos, culturales, simbólicos y emocionales. Si la categoría sentido y significado ha tomado una nueva dirección, lo ha hecho como un sentido producido, el cual es generado por medio del juego recíproco pero, al mismo tiempo, asimétrico de las relaciones sociales. La asignación de significados y la propia interpretación cultural es necesaria y posible solamente dentro del proceso social en el que son constituidos sobre la base de la clase, con contradicciones y en cada evento complejo y multifacético. De ello se desprende no solo que los significados son producidos socialmente, sino que, de la misma manera, las relaciones sociales y económicas son producidas en la esfera cultural de significado. Como lo afirma Raymond Williams, la cultura es producto y producción de un modo de vida determinado (CEVASCO 2003).

Lo que la mayoría de los historiadores sociales de la primera década del siglo XXI están lejos de defender es un modelo de conocimiento histórico como representación del pasado por medio de una relación de inmediatez con el discurso del documento o por la primacía exclusiva y excluyente de las estructuras objetivas. Esas negaciones no implican reconocer la autonomía de los espacios discursivos en la construcción de lo social, porque ellos son socialmente producidos. Como lo expresan Bonnell y Hunt, la estrategia de análisis es doble. En primer lugar, el mundo es experimentado por medio de las representaciones con que lo abordamos. En segundo lugar, esas categorías de representación no poseen realidad empírica por sí mismas independientemente de su compromiso con el mundo social. De allí que la dimensión cultural de la vida nunca pueda ser autónoma, esto es, divorciada empíricamente del mundo de las fuerzas y prácticas sociales (BONNELL; HUNT 1999, p. 25).

Por otra parte, ese compromiso con el poder condicionante del contexto llevó a los historiadores sociales a enfatizar dos aspectos de la referida reconfiguración de su campo. En primera instancia, se enfatizó el aspecto relativo a los contactos y flujos como un desafío fundamental para situar sus temas de una manera diferente en un marco de mayor de referencia. En ese sentido, la introducción de la dimensión transnacional significa que ese marco ampliado no debe ser simplemente asumido con un carácter inerte sino efectivamente examinado y relacionado con una problemática particular, para discernir en qué medida el fenómeno estudiado es también producto de los contactos, flujos e 
interacciones. En segundo lugar, la historia social en vías de reconfiguración en lo que va del siglo XXI es fundamentalmente política, porque supera la ingenua naturalización del mundo social y rescata la dimensión política como un medio en el cual se reproducen, se negocian y se resisten las relaciones de poder. Es decir, en el contexto actual de la llamada "crisis de los grandes relatos" y de la arremetida de las posiciones que tienden a borrar las fronteras de la disciplina de la historia, haciendo de ella una mera técnica literaria o un género puramente ensayístico, es importante afirmar que si la historia tiene un sentido que es posible desentrañar, lo político y la política son elementos vitales para que la historiografía social contribuya a hacer más inteligible el devenir de las sociedades humanas.

Como lo expresan Bonnell y Hunt, los estudiosos del campo sociohistórico no adoptan una comprensión estrictamente científica de la historia social, pero insisten en las analogías fructíferas con la ciencia; esto es, para ellos, el problema de investigación debe ser cuidadosamente especificado, las evidencias, cuidadosamente interrelacionadas y las comparaciones se deben emplear para garantizar la generalización (BONNELL; HUNT 1999). Para ello, es necesario un pluralismo de estrategias de investigación no formuladas por una imaginación poética, como lo afirmaban algunos posmodernistas, sino que las estrategias deben ser conducidas por normas de investigación racional y ser sometidas a validación (IGGERS 2010, p. 122).

Los postulados programáticos están explicitados, las demandas interpretativas, debatidas; subiste, sin embargo, la brecha entre el discurso y la práctica histórica real de un enfoque sugerente para la indagación histórica.

\section{Referencias bibliográficas}

AHR. Conversation: On Transnational History. American Historical Review, v. 111, n. 5, p. 1140-1469, 2006.

BAKER, Keith Michael. El concepto de cultura política en la reciente historiografía sobre la Revolución Francesa. Ayer: Revista de Historia Contemporánea, n. 62, p. 89-110, 2006.

BONNELL, Victoria E.; HUNT, Lynn (eds.). Beyond the cultural turn: new directions in the study of society and culture. Los Angeles: University of California Press, 1999.

BRANTLINGER, Patrick. A Response to Beyond the Cultural Turn. The American Historical Review, v. 107, n. 107, p. 1500-1512, 2002.

CEVASCO, María Elisa. Para leer a Raymond Williams. Quilmes: Universidad Nacional de Quilmes, 2003.

ELEY, Geoff; NIELD, Keith. El futuro de la clase en la historia: ¿Qué queda de lo social? Valencia: Universitat de València, 2010.

ESPINA PRIETO, Mayra. Complejidad y pensamiento social. Complexus: Revista sobre Complejidad, Ciencia y Estética, v. 1, n. 2, p. 1-38, 2005. 
ESTRELLA GONZÁLEZ, Alejandro. Del representacionismo al giro práctico: una reconstrucción del campo historiográfico desde la década de los 90. Pasado y Memoria: Revista de Historia Contemporánea, n. 4, p. 147179, 2005.

FASS, Paula S. Cultural History/Social History: some reflections on a Continuing Dialogue. Journal of Social History, v. 37, n. 1, p. 39-46, 2003.

GIL PUJOL, Xavier. Notas sobre el estudio del poder como nueva valoración de la historia política. Pedralbes: Revista d`historia moderna, n. 3, p. 6188, 1983.

HERING TORRES. Max S.; PÉREZ BENAVIDES, Amada C. (eds.). Historia cultural, desde Colombia. Bogotá: Universidad de Los Andes, 2012.

IGGERS, Georg. Desafios do século XXI à historiografia. História da historiografia, n. 4, p. 105-124, 2010.

JOYCE, Patrick. Materialidad e historia Social. Ayer: Revista de Historia Contemporánea, n. 62, p. 73-87, 2006.

KOCKA, Jürgen. Looses, Gains and Opportunities: Social History Today, Journal of Social History, v. 37, n. 1, p. 21-28, 2003.

LÜDTKE, Alf. The history of everyday life: reconstructing historical experiences and ways of life. Princeton: Princeton University Press, 1995.

MOREYRA, Beatriz Inés. La historia social en los albores del siglo XXI: innovaciones e identidad. In: GIRBAL-BLACHA, Noemí; MOREYRA, Beatriz Inés. Producción de conocimiento y transferencia en las Ciencias Sociales. Buenos Aires: Imago Mundi, 2011.

NÚÑEZ-SEIXAS, Xosé Manuel. La historia social ante el dominio de la historia cultural: algunas reflexiones. Historia Social, n. 60, p. 180-181, 2008.

RECKWITZ, Andreas. Toward a theory of social practices: a development in culturalist theorizing. European Journal of Social Theory, v. 5, p. 243263, 2002.

REVEL, Jacques. Un momento historiográfico: trece ensayos de Historia social. Buenos Aires: Ediciones Manantial, 2005.

SEWELL Jr., William H. Por una reformulación de lo social. Ayer: Revista de Historia Contemporánea, n. 62, p. 51-72, 2006.

. Logics of history: social theory and social transformation. Chicago: The University of Chicago Press, 2005.

SPIEGEL, Gabrielle M. (ed.). Practicing History. In: New directions in historical writing after the linguist turn, New York: Routledge, 2005.

- La historia de la Práctica: nuevas tendencias en Historia tras el giro lingüístico. Ayer: Revista de Historia Contemporánea, Madrid, n. 62, p. 40, 2006. 
SUNY, Ronald Grigor. Back and Beyond: Reversing the Cultural Turn? American Historical Review, v. 107, n. 5, p. 1476-1499, diciembre 2002.

VENGOA, Hugo F. La historia global y su conveniencia para el estudio del pasado y del presente. Historia Crítica, Bogotá, Edición Especial, p. 300-319, 2009. 